\title{
Persistent electrocution mortality of Egyptian Vultures Neophron percnopterus over 28 years in East Africa
}

\author{
IVAYLO ANGELOV, IBRAHIM HASHIM and STEFFEN OPPEL
}

\begin{abstract}
Summary
Electrocution on poorly designed power poles is increasingly shown to pose a threat for the populations of many large raptors. Here we document that a power line in Sudan continues to cause mortality of Egyptian Vultures Neophron percnopterus, a problem that was first identified in 1984. We suggest that this power line may have caused the death of sufficient Egyptian Vultures to partially explain population declines in the Middle East, from where the electrocuted birds may originate. This report highlights the urgent need to plan and retro-fit power lines in Africa with non-lethal support structures.
\end{abstract}

\section{Introduction}

Electrocution at power lines and support structures is a major cause of non-natural mortality in birds of prey (Lehman et al. 2007). Several populations of raptors are known to be directly affected by electrocution as a result of unsustainably low adult and juvenile survival probabilities (Sergio et al. 2004, González et al. 2007, Jenkins et al. 2010, Boshoff et al. 2011, Guil et al. 2011, Perez-Garcia et al. 2011). Long-distance migratory raptors can suffer from various sources of non-natural mortality along their travel routes, and for many species more information is needed about the sources of mortality on migration.

The Egyptian vulture Neophron percnopterus is a small vulture that breeds in Africa, southern Europe, the Middle East, Central Asia and the Indian subcontinent, and is a long-distance migrant in the northern part of its range. Substantial population declines have been recorded in Europe, Africa and Asia (BirdLife International 2011). Mortality during migration and winter can have a large effect on population trends (Grande et al. 2009), and understanding the causes of mortality outside the breeding season is crucial for the development of conservation plans.

Egyptian Vultures from Europe and a large part of Western Asia migrate to Africa and spend the winter in the Sahel zone and the Afar triangle (Meyburg et al. 2004, Cortes-Avizanda et al. 2011, pers. obs.). Vulture populations in Africa and Europe have suffered from poisoning and direct persecution in the past decades (Thiollay 2006a,b, Hernández and Margalida 2009), but electrocution is another potentially significant source of non-natural mortality (Nikolaus 1984, 2006). The Egyptian Vulture is prone to electrocution due to its habit of perching on power lines in desert areas where no trees are available for roosting (Donázar et al. 2002, pers. obs.). Mortality events at power lines have been found to be common on the Canary Islands (Donázar et al. 2002). In Sudan, Nikolaus (1984, 2006) recorded high mortality due to electrocution among migratory Egyptian Vultures at a migration stopover and wintering site (48 on 2 October 1982; 2 in March 1983; 5 in autumn 2005). Although the electrocution of Egyptian Vultures could be a serious problem in Africa (Nikolaus 1984, 2006), the lack of large-scale surveys hinders any assessment of how pervasive and persistent this problem is. Here we report on the continuing 
high mortality of Egyptian Vultures at this stopover site in Eastern Africa over the past three decades. We use this information to highlight that electrocution could potentially have populationlevel effects on Egyptian Vultures in the Western Palearctic.

\section{Study area and Methods}

The work was conducted along a $31-\mathrm{km}$ long power line connecting Port Sudan $\left(19^{\circ} 36^{\prime} \mathrm{N}, 37^{\circ} 13^{\prime} \mathrm{E}\right)$ and a reservoir in the area of Khor Arba'At $\left(19^{\circ} 50^{\prime} \mathrm{N}, 36^{\circ} 58^{\prime} \mathrm{E}\right)$ on the western Red Sea coast in Sudan (Figure 1). This power line has been in operation since the 1950 (data provided by Sudan Electricity Company), and consists of three overhead conductors supported by two types of poles (Figure 2): tubular and rail steel poles with a T-structure supporting the conductors above the horizontal cross-arm (type 1); and tubular concrete poles with three lateral steel cross-arms inclined at $45^{\circ}$ and attached to the pole at different height on alternating sides (type 2). The distance between two poles is $100 \mathrm{~m}$, both types support similar lengths of the power line, with type 2 poles irregularly interspersed between older type 1 poles.

The first surveys of this power line were conducted in 1982 and 1983 (Nikolaus 1984) and repeated in 2005 (Nikolaus 2006). We repeated these surveys on 30 September and 1 October 2010 to document whether the problem of electrocution persisted 28 years after the first survey. Based

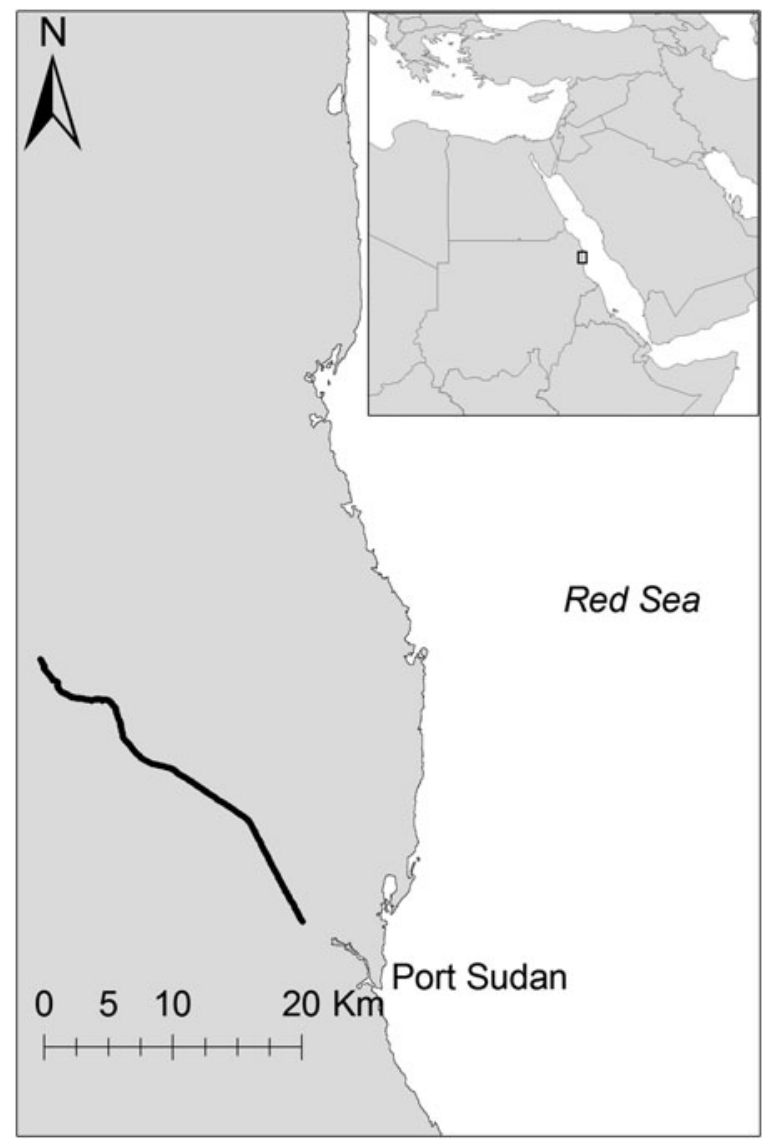

Figure 1. Map detailing the route of the powerline 

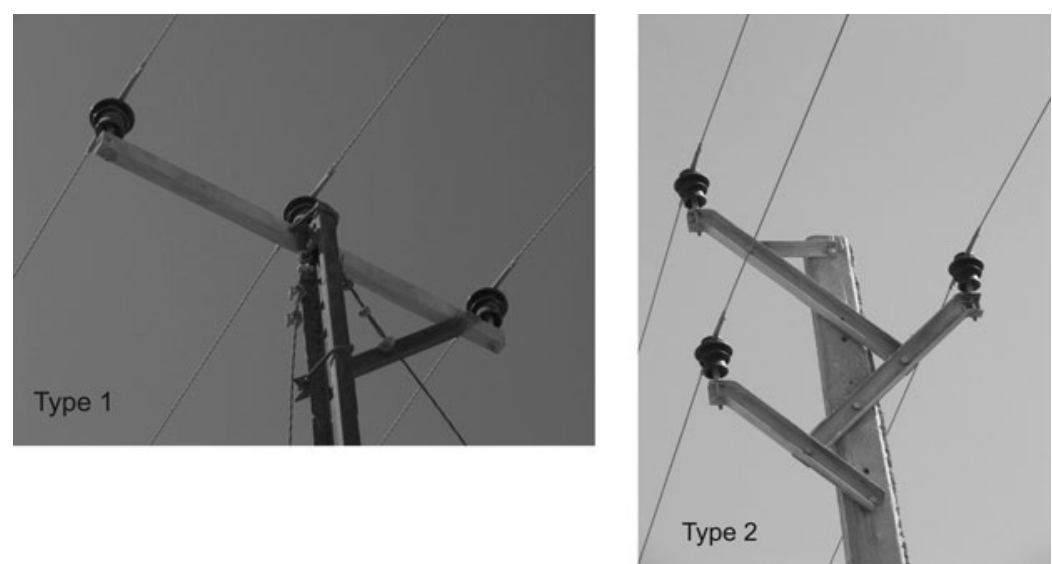

Figure 2. The two types of poles used in the powerline connecting Port Sudan and the reservoir in the area of Khor Arba'Attubular. Type I - rail steel poles with a T-structure supporting the conductors above the horizontal cross-arm; Type 2 - tubular concrete poles with three lateral steel cross-arms inclined at $45^{\circ}$ and attached to the pole at different height on alternating sides.

on the stage of decomposition, we determined the age since death of the carcasses found as: $<1$ month old (complete birds), between 1 and 6 months (scattered parts and remains from birds) and $>6$ months old (most of the remains naturally buried by sand). Because different pylon types vary in their electrocution risk to birds (Lehman et al. 2007, Tintó et al. 2010, Guil et al. 2011) we report our results separately for each type of pylon

\section{Results}

In September 2010, we found carcasses of 17 Egyptian Vultures under the 31-km segment of power line, or 0.055 dead birds per pylon. Among the dead birds were five adults, one in fourth year plumage, five in third year plumage, and three in second year/juvenile plumage. All carcasses were found under power poles; $15(88 \%)$ were found under metal poles (type 1 ) and two (12\%) under concrete poles (type 2). More than half of the carcasses were $>6$ months old $(n=10$; $59 \%)$, and only three carcasses ( $18 \%$ ) were $<1$ month old.

\section{Discussion}

Our recent survey highlights that mortality of Egyptian Vultures in Sudan has persisted for almost three decades despite early warnings that this power line could cause a large number of deaths, especially of migratory individuals (Nikolaus 1984). All the carcasses we found were underneath power poles, and electrocution was the most likely cause of death. The surveyed power line is a small sample of an aging grid of similar structures throughout East Africa. Hence, there is considerable potential for electrocution mortality of both adult and juvenile Egyptian Vultures during their non-breeding period in East Africa, affecting population dynamics of Egyptian Vultures (Grande et al. 2009). As a result, it is possible that the persistent non-natural mortality caused by electrocution in East Africa may have contributed to population declines of this species.

Both a recent survey (Nikolaus 2006) and our survey found fewer Egyptian Vulture carcasses under the same power line than in the 1980 os (Nikolaus 1984). These differences could potentially be caused by lower mortality risk, or by changes in the local scavenger community affecting the persistence of carcasses (Flint et al. 2010, Ponce et al. 2010). Alternatively, the lower number of carcasses found in recent surveys may be a result of the reduction in the species population size. 
Over the past 10 years the older metal pylons (type 1 ) were partly replaced with newer concrete pylons (type 2). We found fewer dead birds under concrete than under metal pylons, hence it is possible that mortality risk may have decreased. However, the power line is still supported by a large number of metal pylons, and we did not find a dead bird under each metal pylon as reported in 1983 (Nikolaus 1984). The replacement of metal by concrete pylons is therefore insufficient as sole explanation for the observed decline in the number of carcasses found. By contrast, large concentrations of Egyptian Vultures had been recorded near Port Sudan in the first half of the $2 \mathrm{O}^{\text {th }}$ century, with roosts of 200 birds on telegraph poles and "many more" roosting on the ground (Meinertzhagen 1954). To our knowledge, nobody has observed or reported such congregations at Port Sudan in the past two decades (Nikolaus 2006), indicating that far fewer birds are exposed to electrocution today than several decades ago. These anecdotal data sources cannot determine whether Egyptian Vultures may have changed their flyway and now use stopover sites outside the study area, or whether populations actually declined. However, the Egyptian Vultures at Port Sudan are attracted to large livestock farms, a slaughter house (about 350 animals slaughtered daily) and vast rubbish dumps, which offer an easily accessible abundance of food. We therefore believe that declining populations, as reported throughout the range of Egyptian Vultures (Baumgart 1991, Khoury 2000; Kirwan et al. 2008, BirdLife International 2011) may be largely responsible for lower numbers of carcasses found during our survey.

The origin of the Egyptian Vultures migrating and wintering along the western coast of the Red Sea is unknown. However, recoveries of two birds ringed in Israel and the former USSR (Ash 1981, Levy 1996) suggest that most of the autumn migrants roosting near Port Sudan may originate from populations in Israel, Syria, Turkey and Jordan rather than from European populations (Meyburg et al. 2004, Ceccolini et al. 2009). In this sense, large population declines have been recorded in these populations (Baumgart 1991, Khoury 2000, Kirwan et al. 2008), with the best studied population being in Israel, where $500-1,000$ pairs were estimated in the middle of the $20^{\text {th }}$ century, declining to 133 pairs in 1986-1989 (Shirihai 1996) and about 40 pairs in 2010 (O. Hatzofe in litt.). It is very likely that the power line near Port Sudan has caused the death of hundreds, perhaps thousands of Egyptian Vultures over the past 50 years. Although speculative, the magnitude of the mortality is fully consistent with observed population declines in potential source populations, and highlights that electrocution-caused mortality may potentially have population-level effects over a broad geographic scale (Boshoff et al. 2011, Guil et al. 2011, Pérez-Garcia et al. 2011).

Given the ongoing increase in the electricity network throughout Sahelian Africa, the introduction of non-lethal installations and retro-fitting of existing structures are sorely needed to reduce electrocution mortality of vultures and other large raptors. Because temporary insulation materials erode over time and retro-fitted pylons may deteriorate to lethal structures in the future, the use of safer pylon designs should be given priority over temporary solutions (González et al. 2007, Guil et al. 2011).

\section{Acknowledgements}

Wildlife Administration in Sudan helped with logistics and communication with authorities and local communities. Funding was provided by the African Bird Club, Mohamed bin Zayed Species Conservation Fund, Vulture Conservation Foundation and the Royal Society for the Protection of Birds. We thank Dobromir Dobrev for designing the map. We appreciate the constructive comments of J. A. Donázar, A. Margalida, and an anonymous reviewer on a previous version of the manuscript.

\section{References}

Ash, J. S. (1981) Bird-ringing results and ringed bird recoveries in Ethiopia. Scopus 5: 85-101.
Baumgart, W. (1991) Gegenwärtiger Status und Gefährdungsgrad von Greifvögeln und Eulen in Syrien. Birds of Prey Bull. 4: 119-131. 
BirdLife International (2011) Species factsheet: Neophron percnopterus. Downloaded from http://www.birdlife.org on 22/04/2011.

Boshoff, A. F., Minnie, J. C., Tambling, C. J. and Michael, M. D. (2011) The impact of power line-related mortality on the Cape Vulture Gyps coprotheres in a part of its range, with an emphasis on electrocution. Bird Conserv. Internatn. 21: 311-327.

Ceccolini, G., Cenerini, A. and Aebischer, A. (2009) Migration and wintering of released Italian Egyptian Vultures Neophron percnopterus. First results. Avocetta 33: 71-74.

Cortés-Avizanda, A., Almaraz, P., Carrete, M., Sánchez-Zapata, J. A., Delgado, A., Hiraldo, F. and Donázar, J. A. (2011) Spatial heterogeneity in resource distribution promotes facultative sociality in two transSaharan migratory birds. PLoS ONE 6: e21016.

Donázar, J. A., Palacios, C. J., Gangoso, L., Ceballos, O., González, M. J. and Hiraldo, F. (2002) Conservation status and limiting factors in the endangered population of Egyptian Vulture (Neophron percnopterus) in the Canary Islands. Biol. Conserv. 107: 89-98.

Flint, P. L., Lance, E. W., Sowl, K. M. and Donnelly, T. F. (2010) Estimating carcass persistence and scavenging bias in a humaninfluenced landscape in western Alaska. J. Field Ornith. 81: 206-214.

González, L. M., Margalida, A., Manõsa, S., Sánchez, R., Oria, J., Molina, J. I., Caldera, J., Aranda, A. and Prada, L. (2007) Causes and spatio-temporal variations of non-natural mortality in the Vulnerable Spanish imperial eagle (Aquila adalberti) during a recovery period. Oryx 41: 495-502.

Grande, J. M., Serrano, D., Tavecchia, G., Carrete, M., Ceballos, O., Tella, J. L. and Donázar, J. A. (2009) Survival in a longlived territorial migrant: effects of lifehistory traits and ecological conditions in wintering and breeding areas. Oikos 118: 580-590.

Guil, F., Fernández-Olalla, M., Moreno-Opo, R., Mosqueda, I., Gómez, M. E., Aranda, A., Arredondo, A., Guzmán, J., Oria, J., González, L. M. and Margalida, A. (2011) Minimising mortality in endangered raptors due to power lines: the importance of spatial aggregation to optimize the application of mitigation measures. PLoS One 6: e28212.

Hernández, M. and Margalida, A. (2009) Poison-related mortality effects in the endangered Egyptian Vulture (Neophron percnopterus) population in Spain: conservation measures. Eur. J. Wildl. Res. 55: 415-423.

Jenkins, A. R., Smallie, J. J. and Diamond, M. (2010) Avian collisions with power lines: a global review of causes and mitigation with a South African perspective. Bird Conserv. Internatn. 20: 263-278.

Khoury, F. (2000) Status of vultures in Jordan. Vulture News 43: 30-36.

Kirwan, G. M., Boyla, K. A., Castell, P., Demirci, B., Özen, M., Welch, H. and Marlow, T. (2008) The birds of Turkey: the distribution, taxonomy and breeding of Turkish birds. London: Christopher Helm.

Lehman, R. N., Kennedy, P. L. and Savidge, J. A. (2007) The state of the art in raptor electrocution research: a global review. Biol. Conserv. 126: 159-174.

Levy, N. (1996) Present status, distribution and conservation trends of the Egyptian Vulture (Neophron percnopterus) in the Mediterranean countries and adjacent arid regions. Pp. $13-33$ in J. Muntaner and J. Mayol, eds. Biology and conservation of Mediterranean raptors. Madrid, Spain: SEO BirdLife.

Meinertzhagen, R. (1954) Birds of Arabia. Edinburgh, UK: Oliver \& Boyd.

Meyburg, B.-U., Gallardo, M., Meyburg, C. and Dimitrova, E. (2004) Migrations and sojourn in Africa of Egyptian Vultures (Neophron percnopterus) tracked by satellite. J. Ornith. 145: 273-280.

Nikolaus, G. (1984) Large numbers of birds killed by electric power line. Scopus 8: 42.

Nikolaus, G. (2006) Where have all the African vultures gone? Vulture News 55: 65-67.

Perez-Garcia, J. M., Botella, F., SanchezZapata, J. A. and Moleon, M. (2011) Conserving outside protected areas: edge effects and avian electrocutions on the periphery of Special Protection Areas. Bird Conserv. Internatn. 21: 296-302. 
Ponce, C., Alonso, J. C., Argandoña, G., García Fernández, A. and Carrasco, M. (2010) Carcass removal by scavengers and search accuracy affect bird mortality estimates at power lines. Anim. Conserv. 13: 603-612.

Sergio, F., Marchesi, L. and Penteriani, V. (2004) Electrocution alters the distribution and density of a top predator, the eagle owl Bubo bubo. J. Appl. Ecol. 41: 836-845.

Shirihai, H. (1996) The birds of Israel. London, UK: Academic Press.
Thiollay, J.-M., (2006a) The decline of raptors in West Africa: long-term assessment and the role of protected areas. Ibis 148: $240-$ 254.

Thiollay, J.-M. (2006b) Severe decline of large birds in the northern Sahel of West Africa: a long-term assessment. Bird Conserv. Internatn. 16: 353-365.

Tintó, A., Real, J. and Mañosa, S. (2010) Predicting and correcting electrocution of birds in Mediterranean areas. J. Wildl. Manage. 74: 1852-1862.

\section{IVAYLO ANGELOV}

Bulgarian Society for the Protection of Birds (BSPB), BirdLife partner in Bulgaria, Haskovo 6300, P.O.Box 130, 41 Bulgaria blvd, Bulgaria.

\section{IBRAHIM HASHIM}

Sudanese Wildlife Society, P. O. Box 6041 Takamul, Khartoum, Sudan: Cola building, $2^{\text {nd }}$ floor, room № 12 B.

\section{STEFFEN OPPEL}

Royal Society for Protection of Birds (RSPB), The Lodge, Sandy, Bedfordshire SG19 2DL, UK.

${ }^{*}$ Author for correspondence; email: ivailo.angelov@bspb.org

Received 16 May 2011; revision accepted 25 November 2011;

Published online 28 March 2012 